find a single space-time diagram in it.

Having made my complaints, I must confess I quite liked the book. All that is wrong with it is the market it is aimed at. It is basically an anecdotal history, and as such is more likely to interest astronomers than the general public. It provides a personal dimension which is normally absent in original papers and review articles. Sullivan records the comments of scientists in the process of discovering, debating or just feeling confused. The result is somewhat chaotic, but that is what science is often like. Sullivan himself describes his book as "an ongoing scientific mystery story". He provides an excellent set of "Selected References", the main merit of which is that they are not selected. Most of them are very inappropriate for laymen, but they are precisely what is required by astronomers wishing to get to the science behind the anecdotes. The book would be improved by the removal of some of the weaker attempts at popularization, such as the summing-up of diffraction as "light plus light equals darkness". There are a few inaccuracies, like the statement that in an accretion disk "gas would spiral in more rapidly were it not for friction". (Gas would not spiral in at all were it not for friction.) I can nevertheless recommend this book for the history section of any astronomical library. I would recommend Kaufmann's book to any layman who wants to know about black holes.

R.L. Znajek is a King's College Research Fellow at the Institute of Astronomy, Cambridge, UK.

\section{Thames revival}

\section{R.J. Wootton}

The Tidal Thames. By Alwyne Wheeler. Pp.228. (Routledge and Kegan Paul: London and Boston, 1979.) £8.95.

THE tidal Thames runs from Teddington Lock, west of London, eastwards to the North Sea. Bisecting the capital city, this length of the river has streamed through British history, providing a means of transport for men and their commerce. Until the nineteenth century, it also supported flourishing fisheries which supplied London with such esteemed food fish as salmon, smelts, eels and whitebait. But thereafter a combination of events destroyed these fisheries and left a long stretch of the tidal river apparently lifeless. Only in the past two decades has this degradation of the river been reversed, and now fish can once again be found throughout the tidal Thames. Alwyne Wheeler, an ichthyologist at the British Museum (Natural History), has played an important role in recording the return of fish to the Thames. His book tells of the death and revival of the river as a habitat fit for fishes.

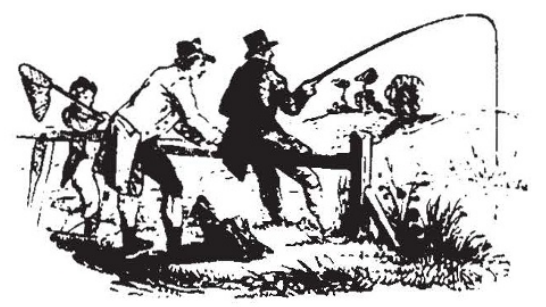

In the first half of the book, Wheeler describes the decline in quality of the river and its effects on the fisheries. Industrialization and population growth were the major factors. Pound locks were constructed to improve navigation on the river, but these hindered the movements of migratory fish and made their capture easier. Gas works and other industries poured their toxic by-products into the river. The primitive methods for the disposal of human excrement, cess pits with the night soil spread on agricultural land, became inadequate so that disposal through sewers was introduced, a development encouraged by recurrent outbreaks of cholera. At first the sewers discharged directly into the river in London, but this led to such gross pollution that on an infamous occasion in 1858, "the year of the great stink", committee meetings in the Houses of Parliament were suspended because of the stench. A great Victorian engineering scheme was initated, and in a few years 84 miles of sewers had been built which carried London's wastes eastwards to empty into the river downstream of central London. Sadly, the site for the outfalls was miscalculated, and the sewage was trapped in the water mass by tidal movements. This area of the river, receiving most of London's excrement, became so polluted it was claimed that suicides died of poisoning before they could drown themselves. If the outfalls had been a few miles downstream it is possible that the Thames would never have become lifeless. Although the situation had improved by the beginning of the twentieth century, two world wars, and the continued growth of population in the London area without adequate provision for sewage treatment, meant that by the 1950 s there were no established fish populations in the Thames over a distance of $69 \mathrm{~km}$. Most of this stretch had extremely low dissolved oxygen concentrations, the consequence of the massive organic pollution.

This intolerable state was recognized and major improvements in sewage treatment started. The effect of these improvements on the fish fauna was monitored in an original way. Wheeler arranged for the collection of fish caught on the filter screens of electricity generating stations which extracted cooling water from the Thames. These collections yielded a clear picture of the recovery of the fish fauna, as both the number of species and the number of individuals increased. This picture of a cleaner river was emphasized dramatically when salmon were recorded in the Thames for the first time in 140 years.

The second half of the book is a detailed description of the results of Wheeler's and other coilections made since 1967, in which 72 species were recorded. This section makes difficult reading. Much of the quantitative data could have been relegated to an appendix for, as Wheeler himself notes, the method of collection provided a qualitative rather than quantitative picture of the recovery of the fish fauna. Yet some of the detail is inadequate: for some species inadequate morphological detail is given; and authorities are not given for the specific names while some common names are used inconsistently.

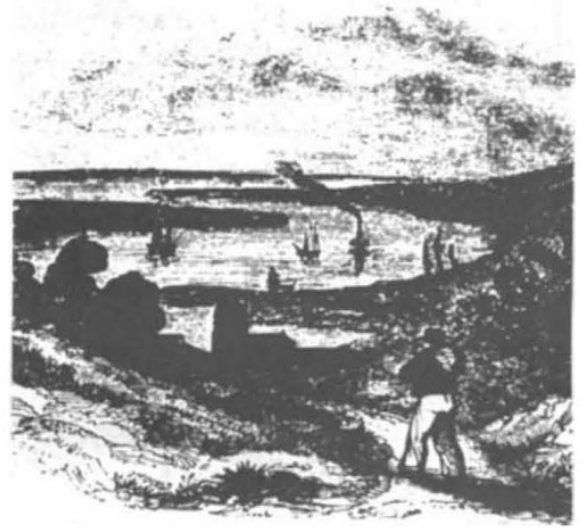

Finally, Wheeler notes that a cleaner river is more sensitive to environmental disturbances which would have been insignificant when the river was lifeless. Potential hazards include the effects of large power stations on water temperature and hence dissolved oxygen, the discharge of raw sewage during storm overflow, and the effects of flood prevention schemes. Although it is unlikely that commercial fishing will again flourish in the tidal Thames, the aesthetic and recreational benefits provided by established fish populations are incalculable. Wheeler's book illustrates how effective public spending, which is now under attack, can be in a civilized, industrialized state.

Although there are a few typographical errors and mistakes of chronology, the book is reasonably priced. Many of the illustrations are taken from Yarrell's British Fishes (1859), which links Wheeler's book with that of a naturalist familiar with the Thames before it died of pollution.

R.J. Wootton is Lecturer in Zoology at the University College of Wales, Aberystwyth, UK. 